\title{
DEXMEDETOMIDINE REDUCES AGITATION AND PROVIDES SMOOTH EXTUBATION AFTER PAEDIATRIC ADENOTONSILLECTOMY
}

\begin{tabular}{ll}
\hline Anesthesiology & \\
Dr. Mehak Gul & Senior Resident, Department of Anaesthesia and Critical Care, SKIMS, Soura . \\
\hline $\begin{array}{ll}\text { Dr. Umar Nisar } \\
\text { Shah* }\end{array}$ & $\begin{array}{l}\text { Senior Resident, Department of Anaesthesia and Critical Care, SKIMS, Soura. } \\
\text { *Corresponding Author }\end{array}$ \\
\hline
\end{tabular}

Dr. Mohd Rafi Denthoo

\author{
Senior Resident, Department of Anaesthesia and Critical Care, SKIMS, Soura.
}

Dr. Basharat Ahad Professor and Head, Department of Anaesthesia and Critical Care, SKIMS, MC Bemina .

\section{ABSTRACT}

OBJECTIVES : To study the role of dexmedetomidine on emergence agitation and its effect on extubation in paediatric adenotonsillectomy. Our study involves the assessment of postoperative pain by Objective Pain Scale and need for rescue analgesia and other untoward events in PACU. The study also included the comparision of post operative recovery time by Modified Aldrete Recovery Score using dexmedetomidine and normal saline in adenotonsillectomy for pediatric patients.

METHODS : After induction of general anesthesia patient was put on controlled ventilation and maintained on sevoflurane $1.5-2 \%$ with $66 \% \mathrm{O}_{2}$ and $33 \% \mathrm{~N}_{2} \mathrm{O}$. At the end of surgery patients received either dexmedetomidine or normal saline over a period of 5 minutes, sevoflurane and nitrous oxide were discontinued, and residual muscle relaxation was reversed. Tracheal extubation time (time from anesthetic gas discontinue to tracheal extubation) and emergence time (time from anesthetic gas discontinue to eye opening on command) were recorded. Incidence of untoward airway events after extubation were also noted. The subject's postoperative behaviour was assessed using Pediatric Anesthesia Emergence Delirium (PAED). In PACU, the intensity of pain was assessed by using an observational pain score (OPS). Any untoward events were noted and patient was shifted as per modified PACU score.

RESULTS: In this randomized comparative study, single dose of dexmedetomidine $(0.5 \mathrm{mcg} / \mathrm{kg})$ was found to be associated with a statistically significant decrease in the incidence of emergence agitation along with smooth extubation in pediatric patients undergoing adenotonsillectomy with sevoflurane anesthesia. In addition, lower incidence of post-operative nausea and vomiting, lower pain score and shorter duration of stay in post-anesthesia care unit were observed. Although it was seen that the extubation was prolonged in the dexmedetomidine group in comparison to the placebo.

CONCLUSION: Dexmedetomidine reduces emergence agitation and provides smooth extubation in pediatric adenotonsillectomy patients on sevoflurane anesthesia.

\section{KEYWORDS}

\section{INTRODUCTION}

Approximately four million children undergo general anesthesia each year in the United States ${ }^{1}$. Pediatric patients present unique anatomical, physiological and pharmacological considerations for anesthetic management. Pediatric patients develop severe anxiety in the preoperative holding area, as well as during induction of anesthesia

One of the most common inhalation anesthetic agents used in pediatric general anesthesia is sevoflurane. Sevoflurane is a volatile anesthetic that allows for a rapid induction as well as timely emergence related to its low blood gas coefficient. It also causes least airway irritation and has greater hemodynamic stability. However, sevoflurane has been associated with an incidence rate of emergence agitation as high as $80 \%$ in children ${ }^{2}$.

Adenotonsillectomy is the major ambulatory surgical procedure most frequently performed in children ${ }^{3,4}$. Emergence Agitation is frequently seen in children between 2 and 5 years of age and is one of the postoperative complications after adenotonsillectomy ${ }^{5}$. Although Emergence Agitation is transient but is distressing for parents and staff. The incidence of Emergence Agitation is wide ranging in the literature from $10 \%$ to $80 \%{ }^{6,7}$. Emergence Agitation presents with symptoms such as combative movements, excitability, thrashing, disorientation and inconsolable crying which can cause injury to the patient or damage to the surgical site ${ }^{8}$. Emergence Agitation may also lead to self extubation or removal of catheters leading to complications such as hypoxia, aspiration pneumonia, bleeding or reoperation. Emergence agitation occurs within first 30 minutes after extubation and is usually self-limiting but sometimes it may be prolonged even upto 2 days. It's etiology is unclear and factors such as pain, rapid recovery, premedication, gender, age, preoperative anxiety and type of surgery such as adenotonsillectomy have been suggested as the causative factors.

Various pharmacological interventions have been used to prevent or limit EmergenceAgitation. Drugs commonly used for prevention of EmergenceAgitation are ketamine ${ }^{10}$, midazolam $^{11}$, propofol ${ }^{12}$, clonidine $^{13}$ and opioids like fentanyl. However, undesirable side effects like sedation, slow awakening, nausea, vomiting, bradycardia, hypotension and in some cases respiratory depression have been noted with these drugs ${ }^{14}$. Dexmedetomidine is an alpha-2 receptor agonist which has been used for adult anesthesia and ICU ${ }^{15,16,17}$. Recently it has been extensively used in pediatric population for postoperative agitation $^{18}$. It causes sedation, hypnosis and anxiolysis without significant respiratory depression. Limited studies have evaluated efficacy of dexmedetomidine for prevention of EA in adult patients undergoing nasal and oral surgery

\section{MATERIALAND METHODS}

After Institutional ethical committee approval and after obtaining a written informed consent from all the patients parent/guardian included in this study, 60 patients of either sex between age group 4-14 years with ASA 1 undergoing elective outpatient adenotonsillectomy were selected for the study. Following patients were excluded from the study : Known allergy to the study medication ,Developmental delay, Upper respiratory tract infection, Congenital abnormalities ,Mental retardation,Attention deficit hyperactivity disorder ,Renal/ liver/ cardiac/respiratory diseases.

During the preoperative visit, all patients were clinically evaluated, assessed and investigated. The study protocol was explained to all the patients / guardians and a written informed consent was taken. No premedication was given.

In the OR equipment for airway management and emergency drugs were kept ready. Patient was shifted to OR. The patient was placed on the operating table and ECG, NIBP, SPO2 were connected to the patient. Preoperative baseline systolic and diastolic BP, HR, SPO2 were recorded. Intravenous line was established. Pre-oxygenation with $100 \%$ oxygen for 3 minutes was done. Intravenous anaesthetic induction was done by propofol $(1-2 \mathrm{mg} / \mathrm{kg})$, fentanyl $(2 \mu \mathrm{g} / \mathrm{kg})$ and atracurium $(0.5 \mathrm{mg} / \mathrm{kg})$; after tracheal intubation, the patients were ventilated. The patients were allocated using simple randomization 
into 2 equal groups. For anaesthesia maintenance all patients were administered sevoflurane $1.5-2 \%$ in $66 \%$ nitrous and $33 \%$ oxygen with controlled ventilation. The heart rate, peripheral oxygen saturation, blood pressure were monitored. The BP and HR were maintained between 80 and $120 \%$ of the preoperative values by increasing or decreasing the concentration of sevoflurane until the completion of surgery. About $5 \mathrm{~min}$ before the end of surgery, patients received either dexmedetomidine or placebo. The anaesthesiologist was blinded to the drug.

- GROUP A (control group): the patients received normal saline $5 \mathrm{ml}$ over a period of 5 minutes at the end of surgery

- GROUP B (dexmedetomidine group):the patients received dexmedetomidine $0.5 \mathrm{mcg} / \mathrm{kg}$ IV diluted in $5 \mathrm{ml}$ of normal saline over a period of 5 minutes at the end of surgery

At the conclusion of the procedure, sevoflurane and nitrous oxide were discontinued, and residual muscle relaxation was reversed with neostigmine $60 \mathrm{mcg} / \mathrm{kg}$ and glycopyrrolate $10 \mathrm{mcg} / \mathrm{kg} \mathrm{IV.}$ Oropharyngeal secretions were aspirated prior to extubation. After tracheal extubation, $100 \%$ oxygen was given via a facemask for $5 \mathrm{~min}$. Tracheal extubation time (time from anesthetic gas discontinue to tracheal extubation) and emergence time (time from anesthetic gas discontinue to eye opening on command) were recorded. Incidence of untoward airway events after extubation such as breath holding (holding breath for $20 \mathrm{~s}$ or more after the extubation was accepted as breath holding) severe coughing or strain (severe coughs was defined as 4 or more coughs and $\mathrm{SpO} 2<95 \%$ ) were recorded.

The blinded research observer recorded the subject's postoperative behaviour, which was assessed using Pediatric Anesthesia Emergence Delirium (PAED) Scale to assess the EA (minimal score is 0 and maximal score is 20 . The degree of EA directly increases with the total score. In PAED of 16 or more, the child was considered agitated. The child was scored at 4 points of time that is on arrival, 15 minutes, 30 minutes and 60 minutes. In PACU, the intensity of pain was assessed by using an observational pain score (OPS). The observer scored pain in a similar way into (none/insignificant pain $(1-3)$, moderate pain (4-6), severe pain (7-10). Patients with pain score 4 or more were treated with additional dose of fentanyl. Vomiting was treated with metoclopramide $0.15 \mathrm{mcg} / \mathrm{kg}$ IV and the incidence of vomiting was recorded

The patients were transferred to the ward according to modified Aldrete score criteria. Patients who had an Aldrete score $>9$ without vomiting were discharged from PACU to surgical ward.

\section{STATISTICALMETHODS:}

The recorded data was compiled and entered in a spreadsheet (Microsoft Excel) and then exported to data editor of SPSS Version 20.0 (SPSS Inc., Chicago, Illinois, USA). Continuous variables were expressed as Mean $\pm \mathrm{SD}$ and categorical variables were summarized as frequencies and percentages. Graphically the data was presented by bar diagrams and line diagrams. Kolmogrov-Simrov test and normal probability plot were used to test for normality of data. Normally distributed continuous variables were compared using student $t$-test, and non-normally distributed variables were analyzed using MannWhitney $U$-test. Chi-square test or Fisher's exact test, whichever appropriate, was employed for comparing categorical variables. A Pvalue of less than 0.05 was considered statistically significant. All Pvalues were two tailed.

\section{OBSERVATIONAND RESULTS}

The patients were divided into two groups: group A and group B. Patients in group B received $0.5 \mathrm{mcg} / \mathrm{kg}$ of Dexmedetomidine at the end of surgery and patients in group A received same dose of normal saline at the end of surgery. The demographic characteristics (including age, weight, and gender) were compared between the groups. Also the EmergenceAgitation score and pain score were measured.

\begin{tabular}{|c|c|c|c|c|c|}
\hline \multicolumn{6}{|c|}{ Table 1: Age distribution of study patients in two groups } \\
\hline Age (years) & N & Mean & SD & Range & P-value \\
\hline Group A & 30 & 8.6 & 2.62 & $5-13$ & \multirow{2}{*}{0.411} \\
\hline Group B & 30 & 9.2 & 2.98 & $4-14$ & \\
\hline
\end{tabular}

Table 1 shows the age distribution of the patients taking part in the study. 30 patients were taken in each group. The age in placebo group ranged from 5-13 years and in dexmedetomidine group from 4-14 years. Age was comparable in the two groups.

\begin{tabular}{|c|c|c|c|c|c|}
\hline \multirow[t]{2}{*}{ Gender } & \multicolumn{2}{|c|}{ Group A } & \multicolumn{2}{|c|}{ Group B } & \multirow[t]{2}{*}{ P-value } \\
\hline & No. & \%age & No. & \%age & \\
\hline Male & 13 & 43.3 & 15 & 50.0 & 0.605 \\
\hline Female & 17 & 56.7 & 15 & 50.0 & \\
\hline Total & 30 & 100 & 30 & 100 & \\
\hline
\end{tabular}

Table 2 shows the distribution of gender in each group. There were 13 males vs. 17 females in control group while the number was equivalent in dexmedetomidine group. The gender distribution was comparable.

\begin{tabular}{|c|c|c|c|c|c|}
\hline \multicolumn{7}{|c|}{ Table 3: Showing average weight (kg) of study patients in two } \\
groups \\
\cline { 1 - 5 } Weight (kg) & N & Mean & SD & Range & P-value \\
\hline Group A & 30 & 21.38 & 6.54 & $11.5-33$ & 0.523 \\
\hline Group B & 30 & 22.53 & 7.29 & $10-34$ & \\
\hline
\end{tabular}

Table 3 shows the weight distribution of patients in the study. The mean weight in the study group was $22.53 \mathrm{~kg}$ with $\mathrm{SD} \pm 7.29 \mathrm{~kg}$ whereas in control group mean was $21.38 \mathrm{~kg}$ with $\mathrm{SD} \pm 6.54 \mathrm{~kg}$. The results are comparable between the two study groups.

\begin{tabular}{|c|c|c|c|c|c|}
\hline \multicolumn{7}{|c|}{ Table 4: Comparison based on duration of surgery (minutes) } \\
in two groups \\
\cline { 1 - 5 } $\begin{array}{c}\text { Duration of Surgery } \\
\text { (Minutes) }\end{array}$ & N & Mean & SD & Range & P-value \\
\hline Group A & 30 & 43.33 & 9.23 & $30-55$ & 0.298 \\
\hline Group B & 30 & 41.17 & 6.52 & $30-50$ & \\
\hline
\end{tabular}

Table 4 shows the comparison of duration of surgery in the two groups. The mean duration of surgery in study group was 41.17 with $\mathrm{SD} \pm 6.52$ minutes and in control group was 43.33 with $\mathrm{SD} \pm 9.23$ minutes. The duration of surgery was comparable in the two groups $(\mathrm{P}>0.05)$.

\begin{tabular}{|c|c|c|c|c|c|}
\hline \multicolumn{7}{|c|}{ Table 5: Comparison based on extubation time (minutes) } \\
in two groups \\
\hline Extubation Time & N & Mean & SD & Range & P-value \\
\hline Group A & 30 & 11.47 & 1.757 & $9-14$ & $<0.001^{*}$ \\
\hline Group B & 30 & 16.93 & 1.856 & $14-20$ & \\
\hline
\end{tabular}

\section{*Statistically Significant Difference $(P-$ value $<0.05)$}

Table 5 shows the difference in extubation time in the two groups. The patients receiving dexmedetomidine had prolonged extubation time with mean of 16.93 with $\mathrm{SD} \pm 1.856$ minutes. The placebo group had a mean of 11.47 with $\mathrm{SD} \pm 1.757$ minutes. The difference was statistically significant with $\mathrm{P}$ value $<0.001$.

Table 6: Comparison based on emergence time (minutes) in two groups

\begin{tabular}{|c|c|c|c|c|c|}
\hline Emergence Time & N & Mean & SD & Range & P-value \\
\hline Group A & 30 & 6.87 & 1.358 & $5-9$ & $<0.001^{*}$ \\
\hline Group B & 30 & 9.83 & 1.556 & $9-14$ & \\
\hline
\end{tabular}

*Statistically Significant Difference $(P$-value $<0.05)$

Table 6 represents the emergence time in the two groups. The mean emergence time in group $\mathrm{B}$ was 9.83 min with $\mathrm{SD} \pm 1.556 \mathrm{~min}$ and controls was $6.87 \mathrm{~min}$ with $\mathrm{SD} \pm 1.358 \mathrm{~min}$. The delay seen with dexmedetomidine group was found to be statistically significant $(\mathrm{P}<0.05)$

\begin{tabular}{|c|c|c|c|c|c|}
\hline \multirow[t]{2}{*}{ Emergence agitation score } & \multicolumn{2}{|c|}{ Group A } & \multicolumn{2}{|c|}{ Group B } & \multirow[t]{2}{*}{ P-value } \\
\hline & \begin{tabular}{|l|l|} 
Mean \\
\end{tabular} & SD & Mean & SD & \\
\hline On Arrival to PACU & 13.4 & 3.13 & 8.6 & 3.23 & $<0.001 *$ \\
\hline Postop 15 Min & 7.9 & 3.48 & 4.2 & 1.81 & $<0.001 *$ \\
\hline Postop 30 Min & 5.1 & 1.89 & 2.1 & 0.94 & $<0.001^{*}$ \\
\hline Postop 60 Min & 2.8 & 1.18 & 0.9 & 0.64 & $<0.001^{*}$ \\
\hline
\end{tabular}

\section{*Statistically Significant Difference $(P$-value $<0.05)$}

Table 7 represents the emergence agitation score in the study groups. The EA score was based on the PEAD scale. Patients in dexmedetomidine group had a lower PEAD score on arrival as-well as 60 minutes postoperatively. The placebo group had higher PEAD score during the observation period. The difference was found to be statistically significant with $P$ value $<0.05$.

Table 8: Comparison based on objective pain score in two groups

\begin{tabular}{|c|c|c|c|c|c|}
\hline \multirow{2}{*}{ Pain score } & \multicolumn{2}{|c|}{ Group A } & \multicolumn{2}{c|}{ Group B } & \multirow{2}{*}{ P-value } \\
\cline { 2 - 5 } & Mean & SD & Mean & SD & \\
\hline
\end{tabular}




\begin{tabular}{|c|c|c|c|c|c|}
\hline On Arrival to PACU & 6.5 & 2.19 & 3.8 & 0.87 & $<0.001^{*}$ \\
\hline Postop 15 Min & 4.2 & 1.39 & 2.3 & 0.65 & $<0.001^{*}$ \\
\hline Postop 30 Min & 2.8 & 1.02 & 1.6 & 0.57 & $<0.001^{*}$ \\
\hline Postop 60 Min & 1.7 & 0.66 & 0.7 & 0.52 & $<0.001^{*}$ \\
\hline
\end{tabular}

*Statistically Significant Difference $(P$-value $<0.05)$

Table 8 represents the comparison of objective pain score in the two groups. It was found that the objective pain score was lower in dexmedetomidine group than normal saline group which was statistically significant ( $\mathrm{p}$ value $<0.05$ ).

\begin{tabular}{|c|c|c|c|c|c|}
\hline \multicolumn{7}{|c|}{ Table 9: Showing incidence of emergence agitation in two } \\
groups \\
\cline { 1 - 5 } Emergence Agitation & \multicolumn{2}{|c|}{ Group A } & \multicolumn{2}{c|}{ Group B } & \multirow{2}{*}{ P-value } \\
\cline { 2 - 5 } & No. & \%age & No. & \%age & \\
\hline Present & 11 & 36.7 & 2 & 6.7 & \multirow{2}{*}{$0.012^{*}$} \\
\hline Absent & 19 & 63.3 & 28 & 93.3 & \\
\hline Total & 30 & 100 & 30 & 100 & \\
\hline
\end{tabular}

*Statistically Significant Difference $(P$-value $<0.05)$

Table 9 is depicting the incidence of emergence agitation in the two groups. Emergence agitation was found in $36.7 \%$ of patients in placebo group whereas in dexmedetomidine group $6.7 \%$ of the patients had emergence agitation. The difference was statistically significant with $\mathrm{p}<0.012$.

\begin{tabular}{|c|c|c|c|c|c|}
\hline \multicolumn{6}{|c|}{ Table 10: Comparison based on PACU score in two groups } \\
\hline PACU Score & N & Mean & SD & Range & P-value \\
\hline Group A & 30 & 9.13 & 0.819 & $8-10$ & 0.176 \\
\hline Group B & 30 & 8.87 & 0.681 & $8-10$ & \\
\hline
\end{tabular}

Table 10 represents the comparison of PACU score. In group A mean score based on modified alderete score was 9.13 with $\mathrm{SD} \pm 0.819$ and in group $\mathrm{B}$ mean score was $8.87 \mathrm{SD} \pm 0.681$. The difference was statistically insignificant $\mathrm{P}$ value $>0.05$.

\begin{tabular}{|c|c|c|c|c|c|}
\hline \multicolumn{7}{|c|}{ Table 11: Comparison based on PACU length of stay (Minutes) } \\
in two groups \\
$\begin{array}{c}\text { PACU Length of Stay } \\
\text { (Minutes) }\end{array}$ & N & Mean & SD & Range & P-value \\
\hline Group A & 30 & 45.10 & 8.817 & $28-60$ & $<0.001 *$ \\
\hline Group B & 30 & 33.43 & 7.408 & $20-46$ & \\
\hline
\end{tabular}

*Statistically Significant Difference (P-value $<0.05)$

Table 11 shows the duration of PACU stay in the two groups. In dexmedetomidine group duration of stay was in range of 20-46 minutes whereas in normal saline group it was $28-60$ minutes. The difference was statistically significant $P$ value $<0.001$

\begin{tabular}{|c|c|c|c|c|c|}
\hline \multicolumn{6}{|c|}{$\begin{array}{c}\text { Table 12: Comparison based on total analgesic consumption } \\
\text { (mcg) } \\
\text { in two groups }\end{array}$} \\
\hline Analgesic consumption (mcg) & N & Mean & SD & Range & P-value \\
\hline Group A & 26 & 31.46 & 15.56 & $12.5-60$ & $0.031^{*}$ \\
\hline Group B & 9 & 20.89 & 7.58 & $11.5-30$ & \\
\hline
\end{tabular}

*Statistically Significant Difference $(P-$ value $<0.05)$

Table 12 represents the total analgesia consumption in the two groups. In group A 26 patients needed rescue analgesia with mean value of 31.46 with $\mathrm{SD} \pm 15.56 \mathrm{mg}$ and in group $\mathrm{B}, 9$ patients required rescue analgesia with mean value of 20.89 with $\mathrm{SD} \pm 7.58 \mathrm{mg}$. The difference was statistically significant with P value 0.03 .

\begin{tabular}{|c|c|c|c|c|c|}
\hline \multicolumn{7}{|c|}{ Table 13: Showing incidence of various complications in two } \\
groups \\
\hline Complications & Group A & \multicolumn{2}{c|}{ Group B } & P-value \\
\cline { 2 - 5 } & No. & \%age & No. & \%age & \\
\hline Nausea/ Vomiting & 1 & 3.3 & 4 & 13.3 & 0.353 \\
\hline Severe Coughing & 6 & 20.0 & 0 & 0.0 & $0.024^{*}$ \\
\hline Breath holding & 5 & 16.7 & 1 & 3.3 & 0.353 \\
\hline Bradycardia & 2 & 6.7 & 3 & 10.0 & 0.641 \\
\hline Hypotension & 1 & 3.3 & 2 & 6.7 & 0.554 \\
\hline
\end{tabular}

*Statistically Significant Difference (P-value $<0.05)$

Table 13 shows the incidence of untoward events in the two groups. Six patients in placebo group showed severe coughing, which was statistically significant. While other side effects like nausea, vomiting, breath holding had no statistical signifance.
DISCUSSION

The aim of this study was to determine the role of dexmedetomidine in emergence agitation and extubation in pediatric adenotonsillectomy with sevoflurane anesthesia. This study was carried out in the Department Of Anesthesia Skims Medical College Bemina, after taking informed consent from the parents / guardians of 60 patients included in the study.

\section{The patients were randomised into two groups}

- GROUPA(control group): the patients received normal saline $5 \mathrm{ml}$ over a period of 5 minutes at the end of surgery.

- GROUP B (dexmedetomidine group): the patients received dexmedetomidine $0.5 \mathrm{mcg} / \mathrm{kg}$ IV diluted in $5 \mathrm{ml}$ of normal saline over a period of 5 minutes at the end of surgery.

The following data which was collected and analysed statistically included Demographic data (Age , Weight, Gender),Duration of surgery in two groups,Effect of dexmedetomidine on extubation ,Role of dexmedetomidine on EmergenceAgitation (emergence time, EmergenceAgitation score and incidence of EmergenceAgitation), Assessment of post-operative pain by objective pain scale, PACU score and duration of stay, Need of rescue analgesia, any untoward side effects.

The results of this study indicate that the administration of dexmedetomidine 5 minutes before the end of surgery, at a dose of $0.5 \mathrm{mcg} / \mathrm{kg} \mathrm{I} / \mathrm{V}$, reduces incidence and severity of agitation observed following sevoflurane anesthesia in pediatric patients undergoing adenotonsillectomy, while concomitantly being associated with smoother and quicker extubation.

The mean age of patients in our study in placebo group was 8.6 years with a standard deviation of 2.6 years whereas mean age in case group was 9 years 2 months with standard deviation of 2.98 years. The two groups were comparable in terms of age and the difference was statistically insignificant ( $\mathrm{p}$-value $=0.411)$ table 1 The two groups were comparable in terms of weight and difference was statistically insignificant (p-value 0.523) table 3 Also the gender distribution was comparable in the two groups with p-value 0.605 table2 .Hence no significant demographic differences were observed between the two groups in our study.

The mean duration of surgery (table4), control group was 43.33 minutes with standard deviation of 9.23 minutes whereas in cases duration was 41.17 minutes with standard deviation of 6.52 minutes. Even though the duration of surgery was more in the control group but the duration was comparable in the two groups and difference was statistically insignificant with p-value of 0.298 .

The extubation time ( $\mathrm{min}$ ) in the control group was 11.47 minutes with standard deviation 1.757 and the extubation time in cases was seen to be 16.93 minutes with standard deviation of 1.856 minutes (table 5). There was a delay in the extubation time seen in the dexmedetomidine group. The difference was statistically significant with $\mathrm{p}$-value $<0.001$. The finding of our study is in concordance with $\mathbf{Z h u}$ et $\mathbf{a l}^{20}$. In the analysis of $\mathrm{Zhu}$ et al dexmedetomidine significantly increased extubation time in children undergoing sevoflurane anesthesia in PACU. The effect might be due to the excessive sedation associated with dexmedetomidine. Prolonged extubation time for dexmedetomidine is also in agreement with studies conducted by Cao JLet $\mathrm{al}^{21}$ and Kim $\mathrm{Sy}^{22}$.

In our study the mean time for emergence in group A was 6.87 minutes with standard deviation of 1.358 minutes whereas in group B mean value was 9.83 minutes with standard deviation of 1.556 minutes (table 6). The p-value was $<0.001$ which was statistically significant. The emergence time was seen to be prolonged in dexmedetomidine group which is due to sedative properties of dexmedetomidine. In a study conducted by Guler $\mathbf{G}$ et $\mathbf{a l}^{23}$ the emergence time and extubation time were 2 minutes longer in dexmedetomidine group but the difference was statistically insignificant. The time to extubation and emergence time were noted to be significantly longer in group B compared to group A. The statistically significant difference is not clinically significant.

The subject's postoperative behaviour was assessed using Pediatric Anesthesia Emergence Delirium (PAED) Scale to assess the emergence agitation. In PAED of 16 or more, the child was considered 
agitated. In our study EmergenceAgitation score on arrival in dexmedetomidine was $8.6 \pm 3.23$ and in placebo group mean was $13.4+3.13$ (table 7). The score was measured at 15, 30, 60 minutes postoperatively and it was observed that EmergenceAgitation score was less in dexmedetomidine group than in the placebo group with a decreasing trend. It is consistent with the study done by Huber et $\mathrm{al}^{24}$ wherein the rapid bolus $0.5 \mathrm{mg} / \mathrm{kg}$ injection of dexmedetomidine was administered $5 \mathrm{~min}$ before the end surgery and a significant decrease in the incidence of EmergenceAgitation was seen without causing haemodynamic instability. Though agitation is observed more frequently in paediatric patients, the incidence in adults has been reported at $4.7 \%$ or $21.3 \%$, 25 . EmergenceAgitation is especially common in ENT surgeries with reported incidence of $55.4 \%$. The wide variation in the reported incidence may be attributable to the use of different scoring scale for evaluating EmergenceAgitation. However, association with other factors, such as pain, inhalational anaesthetics, preoperative benzodiazepine use, male gender, age, preoperative anxiety, and type of surgery has been suggested ${ }^{26}$. It is speculated that high frequency of agitation in otolaryngological procedures may be due to a sense of suffocation that occurs in airway procedures. A similar explanation has been offered to explain the higher incidence of nausea and vomiting following these procedures. In previous studies various doses of dexmedetomidine have been used like loading dose $0.5-2 \mathrm{mcg} / \mathrm{kg}$ followed by infusion of 0.4 to 0.70 $\mathrm{mcg} / \mathrm{kg}$, only infusion of $0.2-1 \mathrm{mcg} / \mathrm{kg}$ or only loading dose of $0.5-4$ $\mathrm{mcg} / \mathrm{kg}$; demonstrated significant advantages of dexmedetomidine when compared to placebo. In our study we administered a single loading dose of dexmedetomidine $0.5 \mathrm{mcg} / \mathrm{kg}$ as in studies done by Isik B et $\mathrm{al}^{27}$, Ibacache $\mathrm{ME}$ et $\mathrm{al}^{28}$ and Guler $\mathbf{G}$ et $\mathrm{al}^{23}$. Study conducted by Ibacache ME in children undergoing surgery using sevoflurane anesthesia, dexmedetomidine $0.3 \mathrm{mcg} / \mathrm{kg}$ given in 10 minutes after induction reduced the incidence of EmergenceAgitation from $37 \%$ in the control group to $10 \%$. Similar findings were seen by Isik B et al where EmergenceAgitation was $47.6 \%$ in placebo and $4.8 \%$ in dexmedetomidine group. The study conducted by Guler $\mathrm{G}$ also concluded that $0.5 \mathrm{mcg} / \mathrm{kg}$ dexmedetomidine reduces agitation after sevoflurane in children undergoing adenotonsillectomy. Shukry $M$ et $\mathbf{a l}^{29}$ conducted a study on continuous infusion of dexmedetomidine $(0.2$ $\mathrm{mcg} / \mathrm{kg} / \mathrm{hr}$ ) and showed reduction in frequency of Emergence Agitation by $10-26 \%$. A meta analysis conducted by Pickard $\mathbf{A}^{30}$ showed that risk of Emergence Agitation was reduced to 0.22(95\% confidence interval 0.14-0.33). A meta-analysis conducted by Jin-hui et al also found the incidence of emergence agitation to be as high as $40.3 \%$ in placebo group as compared to $13 \%$ in dexmedetomidine group $^{31}$

Dexmedetomidine is a potent $\alpha 2$-agonist and has sedative, analgesic and anxiolytic effects. Therefore potentiation of sedative and analgesic property of dexmedetomidine may be responsible for reduction in incidence of EmergenceAgitation however it is seen that it also prolongs time for extubation and time to respond to verbal commands. Dexmedetomidine acts on the endogenous sleep promoting pathway to induce a more natural sleep like status.

In addition to other variables, pain is one of the major factors influencing the severity and duration of EmergenceAgitation. Adequate analgesia is difficult to achieve in pediatric cases undergoing tonsillectomy. It is thought that relieving pain decreases the incidence of EmergenceAgitation associated with anesthetic agents such as sevoflurane. Several studies demonstrated that regional block ${ }^{32,33}$ opioids $^{34}$ and NSAIDs ${ }^{35}$ decrease the incidence of Emergence Agitation. However EmergenceAgitation has also been reported in non-painful procedures ${ }^{36,37}$. In our study ObjectivePainScale was observed on arrival 15, 30 and 60 minutes. It was seen that the mean ObjectivePainScale values in the placebo group were higher than seen in the dexmedetomidine group. The required dose of fentanyl was significantly lower in group B (dexmedetomidine group) when compared to placebo group. The total analgesia consumption in placebo group had a mean of $31.46 \mathrm{mcg}$ with standard deviation of $15.56 \mathrm{mcg}$ whereas in dexmedetomidine group was $20.89 \mathrm{mcg}$ with standard deviation $7.58 \mathrm{mcg}$ and a statistically significant difference was observed with $\mathrm{p}$ value of 0.031 . Hence dexmedetomidine has been shown to decrease post-operative opioid requirement which is in concordance with the study conducted by Patel $\mathbf{A}$ et $\mathbf{a l}^{38}$. These findings indicate that children who were given dexmedetomidine had lower incidence of Emergence Agitation and had lower pain scores. Dexmedetomidine was seen to have a superior efficacy in alleviating pain and in post-operative management. Dexmedetomidine could appear to be a promising agent in prevention of EmergenceAgitation in children under sevoflurane anesthesia.

The mean duration of length of stay in PACU (table 11) in dexmedetomidine group was 33.43 minutes with standard deviation of 7.408 minutes and in placebo group was 45.10 minutes with standard deviation of 8.817 minutes and the difference was statistically significant with p-value $<0.001$. Also PACU score (table 10) in the placebo group was 9.13 with standard deviation of 0.819 and in group B (dexmedetomidine group) PACU score was 8.87 with standard deviation of 0.681 . Statistically insignificant difference was seen in the two groups with p-value 0.176

Various complications were noted in the two groups like nausea, vomiting, breath holding, bradycardia and hypotension and were comparable in the two groups. Although severe coughing was seen more in placebo group as compared to dexmedetomidine group (pvalue 0.024 ) which was in consistence with the study conducted by Guler G. It was observed that airway complications were less commonly encountered in the dexmedetomidine group. The airway problems seen in placebo group did not necessitate reintubation or medication in our study. Lower airway complications may be attributed to the lesser degree of laryngeal stimulation in this group owing to the sedative and analgesic effects of dexmedetomidine.

\section{CONCLUSION}

It was seen that single dose $(0.5 \mathrm{mcg} / \mathrm{kg})$ dexmedetomidine reduces EmergenceAgitation and provides smooth extubation in pediatric adenotonsillectomy patients on sevoflurane anesthesia. Even though the extubation time was prolonged but there were less side effects noted.

\section{REFERENCES}

Miller JW, Divanovic AA, Hossain MM, Mahmoud MA, Adreas W. Dosing and efficacy of intranasal dexmedetomidine sedation for pediatric transesophageal echocardiography: Retrospective Study. Canadian J Anesthesia. 2016; 63(7): 834-841.

2. Kim YH, Yoon SZ, Lim HJ, Yoon SM. Prophylatic use of midazolam or propofol at the end of surgery may reduce the incidence of emergence agitation after sevoflurane anesthesia. Anesth Intensive Care. 2011;39(5): 904-8

3. Pappas AL, Sukhani R, Hotaling AJ, Mikap-stevens N, Jovorski JJ, Donzelli J et al. The effect of preoperative dexamethasone on the immediate and delayed postoperative morbidity in children undergoing denotonsillectomy Anesth Analg. 1998;87:57-61.

Schoem SR, Watkins GL, Kuhn JJ, Thompson DH Control of early postoperative pain with bupivacaine in pediatric tonsillectomy. ENT J 1993; 72:560-563.

Uysal H, Takmaz SA, Yaman F, Baltaci B, Basar H. The efficacy of intravenous Uysal H, Takmaz SA, Yaman F, Baltaci B, Basar H. The efficacy of intravenous
paracetamol versus tramadol for postoperative analgesia after adenotonsillectomy in paracetamol versus tramadol for postoper
children. J Clin Anesth.2011; 23:53-57.

6. Voepel-Lewis T, Malviya S, Tait AR. A prospective cohort study of emergence agitation in the pediatric postanesthesia care unit. Anesth Analg. 2003;96:1625-30.

Cravero J, Surgenor S, Whalen K. Emergence agitation in paediatric patients after sevoflurane anesthesia and no surgery: a comparison with halothane. Paediatr Anaesth. $2000 ; 10: 419-24$

8. Mountain BW, Smithson L, Cramolini M, Wyatt TH, Newman M. Dexmedetomidine as a pediatric anesthetic premedication to reduce anxiety and to deter emergence delirium. AANAJ.2011; 79:219-224.

9. Lepouse C, Lautner CA, Liu L, Gomis P, Leon A. Emergence delirium in adults in the post-anaesthesia care unit. Br J Anaesth. 2006; 96 : 747-53.

10. Chen JY, Jia JE, Liu TJ, Qin MJ, Li WX. Comparison of the effects of dexmedetomidine, ketamine, and placebo on emergence agitation after strabismus surgery in children. Can JAnaesth. 2013; 60:385-92.

11. Kain ZN, Caldwell-Andrews AA, Maranets I, McClain B, Gaal D, Mayes LC, et al. Preoperative anxiety and emergence delirium and postoperative maladaptive behaviors. Anesth Analg. 2004; 99:1648-54.

12. Abu-Shahwan I. Effect of propofol on emergence behavior in children after sevoflurane general anesthesia. Paediatr Anaesth. 2008;18:55-9.

13. Ghai B, Ram J, Chauhan S, Wig J. Effects of clonidine on recovery after sevoflurane anaesthesia in children undergoing cataract surgery. Anaesth Intensive Care 2010;38:530-7

14. Dahmani S,Stany I, Brasher C,Lejeune C,Bruneau B, Wood C, et al. Pharmacological prevention of sevoflurane and desflurane related emergence agitation in children: $\mathrm{A}$ meta-analysis of published studies. Br J Anaesth. 2010;104:216-23.

15. Mantz J, Josserand J, Hamada S. Dexmedetomidine: New insights. Eur J Anaesthesiol. 2011;28:3-6.

16. Arain SR, Ruehlow RM, Uhrich TD, Ebert TJ. The efficacy of dexmedetomidine versus morphine for postoperative analgesia after major inpatient surgery. Anesth Analg. 2004; $98: 153-8$.

17. Mahmoud M, Mason KP. Dexmedetomidine: Review, update, and future considerations of paediatric perioperative and periprocedural applications and limitations. $\mathrm{Br}$ Anaesth. 2015;115:171-82.

18. Ni J, Wei J, Yao Y, Jiang X, Luo L, Luo D. Effect of dexmedetomidine on preventing postoperative agitation in children: A meta-Analysis. PLoS One. 2015;10:e0128450

19. Kim SY, Kim JM, Lee JH, Song BM, Koo BN. Efficacy of intraoperative dexmedetomidine infusion on emergence agitation and quality of recovery after nasal surgery. Br JAnaesth. 2013; 111:222-8.

20. Zhu M, Wang H, Zhu A, Niu K, Wang G. Meta-analysis of dexmedetomidine on emergence agitation and recovery profiles in children after sevoflurane anesthesia: Different administration and different dosage. PLoS One. 2015; 10: e 0123728.

21. Cao JL, Pei YP, Wei JQ, Zhang YY. Effects of intraoperative dexmedetomidine with intravenous anesthesia on postoperative emergence agitation/delirium in pediatric patients undergoing tonsillectomy with or without adenoidectomy: a CONSORTprospective, randomized, controlled clinical trial. Medicine. 2016; 95(49):e5566.

22. Welborn LG, Hannallah RS, Norden JM, Ruttimann UE, Callan CM. Comparison of emergence and recovery characteristics of sevoflurane, desflurane, and halothane in 
pediatric ambulatory patients. Anesth Analg. 1996; 83: 917-920.

23. Guler G, Akin Z, Tosun E, Eskitascoglu, Mizrak A, Boyaci A. Single-dose dexmedetomidine attenuates airway and circulatory reflexes during extubation. Acta dexmedetomidine attenuates airway and
Anaesthesiol Scand. 2005; 49: 1088-91.

24. Breschan C, Platzer M, Jost R, Stettner H, Likar R. Midazolam does not reduce emergence delirium after sevoflurane anesthesia in children. Paediatr Anaesth. 2007; 17: 347-52.

25. YU D, Chai W, Sun X, Yao L. Emergence agitation in adults: risk factors in 2000 patients. Can JAnesth. 2010; 57(9): 843-8.

26. Eckenhoff JE, Kneale DH, Dripps RD. The incidence and etiology of postanesthetic excitement. Anesthesiology; 1961, 22: 667-73

27. Isik B, Arslan M, Tunga AD, Kurtipek O Dexmedetomidine decreases emergence agitation in pediatric patients after sevoflurane anesthesia without surgery. Paediatr agitation in pediatric patients after

28. Ibacache ME, Muñoz HR, Brandes V, Morales AL Single-dose dexmedetomidine reduces agitation after sevoflurane anesthesia in children. Anesth Analg. 2004; 98 : $60-63$

29. Shukry M, Clyde MC, Kalarickal PL, Ramadhyani U Does dexmedetomidine prevent emergence delirium in children after sevoflurane-based general anesthesia? Paediatr Anaesth. 2005 Dec; 15(12):1098-104.

30. Pickard A, Davies P, Birnie K, et al. Systematic review and meta-analysis of the effect of intraoperative alpha(2)-adrenergic agonists on postoperative behaviour in children. $\mathrm{Br} \mathrm{J}$ Anaesth 2014; 112: 982-990.

31. Kuratani N, OIY: Greater incidence of emergence agitation in children after sevoflurane anesthesia as compared with halothane. A meta analysis of randomized controlled trials. Anesthesiology. 2008; 109:225-32.

32. Jin-Hui C, Yong-qi Y, Hui-Jun C, he H, ya C, Ze-ping D. Effects of dexmedetomidine in postoperative recovery profile after sevoflurane anesthesia in pediatric patients: a metaanalysis. JAnesth Clin Res. 2013; 4: 369 .

33. Ghosh SM, Agarwala RB, Pandey M, Vajifdar H. Efficacy of low-dose caudal clonidine in reduction of sevoflurane induced agitation in children undergoing urogenital and lower limb surgery: a prospective randomised double-blind study. Eur J Anaesthesiol. 2011;28: 329-33.

34. Sinha A, Sood J. Caudal block and emergence delirium in pediatric patients: is it analgesia or sedation? Saudi J Anaesth. 2012;6:403-7.

35. LiX, ZhangY, ZhouM, XiaQ, LiW, LuQ. The effect of small dose sufentanil on emergence agitation in preschool children following sevoflurane anesthesia for elective repair of unilateral inguinal hernia. Saudi Med J. 2013;34: 40-5.

36. Breschan C, Platzer M, Jost R, Stettner H, Likar R. Midazolam does not reduce emergence delirium after sevoflurane anesthesia in children. Paediatr Anaesth. 2007; 17: $347-52$.

37. Hauber JA, Davis PJ, Bendel LP, Martyn SV, McCarthy DL, Evans MC, et al. Dexmedetomidine as a rapid bolus for treatment and prophylactic prevention of emergence agitation in anesthetized children. Anesth Analg. 2015;121:1308-15

38. Davis PJ, Greenberg JA, Gendelman M, Fertal K. Recovery characteristics of sevoflurane and halothane in preschool-aged children undergoing bilateral myringotomy and pressure equalization tube insertion. Anesth Analg. 1999;88:34-8 